\title{
An oral health survey of vulnerable older people in Belgium
}

\author{
Luc De Visschere $^{1,2}$ • Barbara Janssens ${ }^{1,2}$ - Griet De Reu ${ }^{1}$ Joke Duyck ${ }^{2,3}$. \\ Jacques Vanobbergen ${ }^{1,2}$
}

Received: 12 December 2014 / Accepted: 9 November 2015

(C) Springer-Verlag Berlin Heidelberg 2015

\begin{abstract}
Objectives The aim of this study was to gain insight in the oral health of persons aged 65 years or more.

Materials and methods Data were obtained from 652 vulnerable older persons $(\geq 65)$ by means of a clinical oral examination. Additional demographic data were gathered including age, gender, residence, and care dependency.

Results The mean age of the total study sample was 83 (7.7) years and $71 \%$ was female. Nearly $33 \%$ of the sample was living at home with support, and $67 \%$ was residing in nursing homes. The number of occluding pairs was low and the proportion of edentulous people was highest among persons with the highest care dependency. The mean Decay-missingfilled teeth index (DMFT) was $20.3(9.0)$. A prosthetic treatment need and inadequate oral hygiene levels were observed in $40 \%$ and more than $60 \%$ of the subjects, respectively. The highest treatment need was observed in the oldest age group
\end{abstract}

Luc De Visschere

Luc.DeVisschere@UGent.be

Barbara Janssens

barbarae.janssens@ugent.be

Griet De Reu

griet.dereu@ugent.be

Joke Duyck

joke.duyck@uzleuven.be

Jacques Vanobbergen

jacques.vanobbergen@ugent.be

1 Department of Community Dentistry and Oral Public Health, Dental School, Ghent University, 185, De Pintelaan, 9000 Ghent, Belgium

2 BENECOMO, Flemish-Dutch Geriatric Oral Health Research Group, Ghent University, 185, De Pintelaan, 9000 Ghent, Belgium

3 Department of Oral Health Sciences, KU Leuven, Leuven, Belgium and the highest mean dental plaque in older persons with the highest care dependency.

Conclusions The oral health in frail older people in Belgium is poor. The restorative and prosthetic treatment need is high and oral hygiene levels are problematic. Age, residence, and care dependency seemed to have some influence on oral health parameters.

Clinical significance In the long term, the most important future challenge of oral health care policies is to identify older adults before they begin to manifest such oral health deterioration. Regular dental visits should be strongly promoted by all (oral) health care workers during the lifespan of all persons including older adults.

Keywords Oral health · Treatment need · Vulnerable elderly · Epidemiological study

\section{Introduction}

Worldwide, the absolute number and proportion of older people within society is increasing and will continue to do so for the next century. This phenomenon is occurring also in Belgium, accompanied by an expected (until 2050) significant increase in the number of older people with disabilities [1]. On March 31, 2007, 257,000 older Belgians (2.4\% of the total population) were eligible to receive remunerated health care based on their care dependency. Of these, $53 \%(136,830)$ were residing at home supported by home care and $47 \%$ $(120,170)$ were living in nursing homes [2].

A nursing home is an intramural residential setting where physically or mentally impaired, frail older people live and receive both personal and nursing care provided by registered nurses and care-aides [3]. In Belgium, intramural care is well organised by the over 1600 nursing homes across the country. 
Nevertheless, the Belgian authorities want to ensure that older people are provided with a service that enables them to live for as long as they can in their own homes. Nevertheless, once staying at home with home care is no longer an option, admission to a nursing home is in most cases inevitable. Relative to their care dependency, older people residing in nursing homes are entitled to receive daily care, including oral health care.

The rationale for including oral health care is based upon oral health being an essential and integral part of the general health with an impact on the quality of life during a person's lifespan. The World Oral Health Report 2003 [4] outlines important principles for disease control and oral health promotion in the twenty-first century, as oral health is a determining factor for quality of life and is strongly associated with general health. These principles remain important until the end of life. Yet, oral health is often neglected in general health promotion.

In Belgium, very few data have been published on the dental status of older people. In Flanders, about $53 \%$ of individuals aged 65 years or more has retained natural teeth [5]. This proportion drops to $36 \%$ among nursing home residents [6]. This proportion is comparable to that in the Netherlands (30\%) [7] and Norway (34\%) [8] but lower than that in Sweden (58\%) [9], Italy (57\%) [10], and Germany (47\%) [11] and much lower than that in France (73\%) [12]. Common highly prevalent oral health problems in older people are tooth decay (especially root surface decay), gingival inflammation, denture-related oral mucosal lesions, and hypo-salivation [13-25]. The medical, dental, and nursing literature provides strong evidence that adequate oral hygiene is an important determining factor for oral health. Studies, performed in different European countries, reveal inadequate levels of oral hygiene in the institutionalised older people [6, 7, 9-11, 17, 19, 21, 24].

In Belgium, like in many countries worldwide, there is a growing concern about the oral health of older people. In 2010, a national survey on the oral health of persons with special needs (people with disabilities and frail older people) was conducted by the Dental Association (VVT) and the universities of Ghent and Leuven. This national survey was ordered by the National Institute for Health and Disability Insurance (NIHDI) to monitor the oral health of groups with special needs including vulnerable older people in all three regions in Belgium (Flanders, Brussels, and Walloon). Epidemiological oral health data on children and adults with disabilities were recently reported [26-28].

The aim of the present study was to gain insight in the oral health data of older persons aged 65 years or more. The oral health aspects of interest were the dental and prosthetic status, the restorative index, and the prosthetic treatment need along with the dental and denture hygiene levels. Additionally, the aim was rendered into the following research question: is there any statistically significant difference between oral health parameters depending on age, gender, residence, and care dependency?

\section{Material and methods}

\section{Population and study sample}

All persons aged 65 years or more residing in a nursing home or at home and supported by domiciliary care and eligible for remuneration based on the Katz index [29] formed the target study population $( \pm 257,000)$. All these persons were considered frail older persons belonging to special needs groups. Persons in a temporary care dependency situation or persons in the geriatric, psycho-geriatric, or revalidation wards of hospitals were excluded from the study.

The sampling procedure took into account the proportion of persons residing at home $(53 \%)$ or in nursing homes $(47 \%)$ in the Belgian population both depending on three different managerial umbrellas (private non-profit with an ecclesiastic background, social services, commercial) and the geographical distribution (10 provinces) predetermined by the immediate surroundings of the dental examiners.

The sample was selected by a two-level randomised design. The selection was randomised first according to the different care organisations and, second, according to the individuals within the organisations. Care organisations were selected at random, with a replacement strategy, from a database containing all care organisations in Belgium. Finally, 18 nursing homes in Flanders and 28 in Brussels and the Walloon region agreed to participate, together with 26 home care organisations in Flanders and two in Brussels and the Walloon region. Under the second step, it was intended to select at random 895 older persons belonging to these 74 care organisations, taking into account loss to follow-up at the time of clinical examination. Eight to 15 older persons in each care organisation were selected to participate to the study. A replacement procedure was provided in cases of refusals.

\section{Clinical examinations}

Each participant gave written informed consent for the clinical examination undertaken by one of the 40 (26 Dutch speaking and 14 French speaking) qualified and calibrated dentists recruited for this survey. Room illumination was supported by an eight light-emitting diode advanced headlight and a dental mouth mirror. A conventional periodontal probe was employed. Clinical data with respect to oral infections and oral functionality were recorded on a standard examination sheet. The level of oral functionality was defined as the maintenance of masticatory ability and efficiency while preserving the health of soft and hard tissues counting the number of occluding pairs. The examination included dental status, exposed root surfaces, loss of hard tooth substance (erosion, abrasion, and attrition), Dutch periodontal screening index (DPSI) [30], oral mucosal conditions, oral hygiene, number of occluding pairs, prosthetic status, and prosthetic need. 
The dental status was examined following a detailed dental charting. Possible coding for natural teeth was sound, decayed, restored with decay, restored without decay, extracted because of decay, extracted for other reasons, sealed, presence or replacement by crown/veneer/abutment/pontic, trauma, residual root, not registered, or not possible to register.

The $\mathrm{D}_{3} \mathrm{MFT}$ and the restorative index $(\mathrm{F} / \mathrm{D}+\mathrm{F})$ were calculated from the clinical parameters obtained by the dental status assessment. For the analysis, the restorative index was dichotomised in 1 (fully restored) or less than 1 indicating treatment need. The condition of the root surfaces of the natural teeth (with exclusion of residual roots) was assessed registering the number of sound exposed roots and the number of exposed roots with decay or fillings. In addition, the number of dental implants was registered. Loss of hard tooth substance was registered by indicating the presence (yes/no) of erosion, abrasion, and attrition separately.

The DPSI ${ }^{31}$ screens subjects with minor, moderate and severe periodontal disease. DPSI is scored per sextant and uses the following scores: 0 - healthy; 1 -bleeding on probing with pockets $\leq 3 \mathrm{~mm}$, no calculus, no overhangs of restorations; 2 -bleeding on probing, calculus and/or overhanging restorations with pockets $\leq 3 \mathrm{~mm} ; 3^{-}$-pockets of 4 to $5 \mathrm{~mm}$ without gingival recession; $3+$-pockets of 4 to $5 \mathrm{~mm}$ with gingival recession; and 4 - pockets $\geq 6 \mathrm{~mm}$. Periodontal disease was defined as a DPSI $>0$.

Oral mucosal conditions were registered by ticking one or more of the following lesions: denture ulcer, irritation fibroma, flabby ridge, palatal hyperaemia, hyperkeratosis of the inner site of the cheeks, white lesions not removable by rubbing with gauze, cheilitis angularis, aphthous lesion(s), fistula, others, no lesion, and not possible to register.

The number of functional occluding pairs of natural teeth was calculated by summing each pair of premolars or molars in occlusion. In patients with removable dentures, the number of functional occluding pairs was assessed with dentures. Fixed crowns or bridges were counted as natural teeth and third molars were included.

The prosthetic status was assessed separately for the upper and lower jaws, registering one of the following possibilities: no denture, one bridge, more than one bridge, bridge(s) and acrylic resin-based denture, bridge(s) and metal frame partial denture, only acrylic resin-based denture, only metal frame partial denture, fully removable denture, any kind of removable denture but not worn, and not possible to register.

The prosthetic treatment need was registered by ticking one of following possibilities for the upper and lower removable denture separately: denture renewal is necessary, denture renewal is advisable, denture renewal is not indicated, denture relining or rebasing is necessary, denture relining or rebasing is advisable, denture relining or rebasing is not indicated, denture repair is indicated, and not possible to register.

Oral hygiene was scored for the natural teeth and dentures separately. For the natural teeth, an ordinal score was used according to the Silness and Löe plaque index (range 0 to 3; $0=$ no plaque, $1=$ plaque seen in situ only after using a probe on the tooth surface, 2 moderate accumulation of visible plaque near the gingival border, and $3=$ more than one third of the buccal surface covered with visible plaque) [31]. The measurement of the state of oral hygiene by the Silness-Löe plaque index was based on recording the soft debris deposits on the Ramfjord teeth, if present. Denture plaque on the oral and mucosal surfaces of the dentures was scored using a modified Augsburger [32] technique using four possible scores: no visible plaque, less than $25 \%$ of the surface covered, less than $50 \%$ covered, and more than $50 \%$ covered. According to the instructions, no disclosing solution was used for both dental and denture plaque. Furthermore, the presence (yes/no) of dental and denture calculus was registered.

Additional demographic data were gathered including age, gender, language (Dutch or French), and care dependency. The latter was obtained from the care organisations which all use the Katz index. This index is a tool assessing the residents' ability to perform the activities of daily living - bathing, dressing, toileting, transferring, continence, and feeding - and any cognitive impairment (Table 1).

\section{Dental examiners}

Before the start of the survey, all the dentists recruited were trained and calibrated. The clinical examination parameters were comprehensively explained and discussed using clinical

Table 1 Categories of care dependency based on the Katz index [29]

\begin{tabular}{ll}
\hline Category O & Nearly physically independent and not demented \\
Category A & Physically dependent for bathing and/or dressing \\
& Mentally independent but disoriented in time and space \\
Category B & Physically dependent for bathing, dressing, transferring and/or toileting Mentally dependent, disoriented in time and space \\
Category C & Physically dependent for bathing, dressing, transferring and/or toileting and/or feeding, and incontinent \\
& Mentally dependent, disoriented in time and space \\
Category Cd & Physically dependent for bathing, dressing, transferring and/or toileting and/or feeding, and incontinent. \\
& Dentally dependent, disoriented in time and space
\end{tabular}


cases illustrated by photographs. At the end of the training session, all participating dentists were asked to register independently eight cases for just the relevant parameters. Afterwards, the exact scores of the eight cases were discussed with the participants. Inter-examiner reliability was tested comparing the individual data of the dentists with a reference standard (JV, last author). Kappa and an intra-class correlation coefficient were calculated for categorical and continuous parameters, respectively. The DPSI could not be scored on clinical photographs.

The reliability values for denture calculus, prosthetic status, denture plaque, loss of tooth substance, number of exposed roots, prosthetic treatment need, oral mucosal condition, and dental calculus ranged from 1.0 to 0.5 representing an excellent to fair agreement. Poor agreement $(0.3)$ was found for dental status and the number of occluding pairs.

The study was approved by the Ethical Committee of the University Hospital of Ghent (2010/126).

\section{Statistics}

All data were converted into SAS ${ }^{\circledR}$ files, which were analysed using SAS software version 9.2 (SAS Institute Inc. 2009; Cary, NC). Taking into account all different selection parameters (living situations, managerial umbrellas, regions, provinces, care dependency levels, age, and gender), recording exact selection probabilities was not feasible. Therefore, no weighted analysis is performed and data are analysed assuming to be a random sample.

Chi-square, Kruskal-Wallis, and $t$ tests were performed in order to evaluate the statistical significance of observed differences between subgroups. For all statistical tests, $p$ values below 0.05 were considered statistically significant.

\section{Results}

\section{General characteristics}

Data were recorded from 686 disabled individuals 65 years of age or more - a response rate of $76.6 \%$ with respect to the selected number of 895 individuals. Finally, complete data records of 652 persons could be used for the analyses. The mean age of the total study sample was 83.0 (SD 7.7) years and $71 \%$ was female (Table 2). The proportion of female participants increased with age, reaching nearly $80 \%$ in the oldest ( $>89$ ) age group. The analysis showed that $66 \%$ of the persons examined were Dutch speaking, while French was the mother tongue of $34 \%$. These proportions correspond closely to the proportion of Dutch (62\%) and French (38 \%) speaking persons in Belgium (http://www4.vlaanderen.be/dar/svr/ Cijfers/Pages/Excel.aspx). Nearly $33 \%$ of the sample lived at home supported by domiciliary care and $67 \%$ was residing in nursing homes. Forty-seven percent of the examined persons were characterised by a low care dependency according to the Katz index O or A, while $53 \%$ was highly dependent (Katz index B, C, or Cd). The proportion of older people with a high care dependency $(\mathrm{B}, \mathrm{C}$, or $\mathrm{Cd}$ ) was $62 \%$ among the nursing home residents and $21 \%$ among the individuals residing at home supported by domiciliary care.

\section{Dental status}

Sixty-eight percent $(n=314)$ of the study sample was dentate with a mean number of 7.7 teeth (SD 8.5) (Table 3). The proportion of edentate persons was highest (36\%) in the oldest age group (>89); this compares to $26 \%$ in the youngest age group. More nursing home residents ( $35.7 \%$ ) were edentulous as compared to their counterparts residing at home supported by domiciliary care $(24.2 \%)(p=0.006)$.

The mean number of teeth (residual roots excluded) was higher in the lower jaw 4.3 (SD 4.5) compared to the upper jaw 2.9 (SD 4.3). Although not significant, the number of teeth tended to decrease with increasing care dependency with a mean of 9 (SD 8.8) remaining teeth for the least dependent (O) and 6.3 (SD 8.0) for the highest dependent persons (CD).

With respect to infection control, the oral health status of the hard and soft tissues was examined. In only 15 of 460 dentate older persons, $a \mathrm{D}_{3} \mathrm{MFT}=0$ was calculated. The mean $\mathrm{D}_{3} \mathrm{MFT}$ was 20.3 (SD 9.0). As expected, the proportion of the M component was the highest as compared to the $\mathrm{D}$ and $\mathrm{F}$ components, with an increasing $\mathrm{D}_{3}$ MFT towards the oldest age group. A restorative index of less than one, indicating a need of treatment, was observed in $77 \%$ of the dentate study sample.

Of all participants, attrition was observed in $44 \%$ and abrasion in $22 \%$ of the cases. Erosion could only be detected in one out of ten of the persons examined. The proportions with attrition (47\%) and abrasion (34\%) were highest in the oldest age group. Exposed root surfaces (Table 3) were found in more than $70 \%$ of the dentate older individuals with 9 out of 10 individuals with exposed root surfaces in the age groups of 65 to 79 years old (not significant (NS)). For nearly $50 \%$ of all remaining teeth, in all the persons examined, the root surfaces were exposed. At least one root surface was restored or decayed in $40 \%$ of the dentate cases, and this proportion was highest in the oldest group. Twenty implants were found distributed over 11 individuals: one implant in the upper jaw in two persons and one implant in the lower jaw in four persons. Two implants were found in three persons and two persons had four implants.

Periodontal disease was present in $87 \%$ of the dentate older persons: $18 \%$ with score 1 and $33 \%$ with score 2 . Within the study sample, DPSI values of " $3-$ " ( $8 \%)$, " $3+$ " $(22 \%)$, and " 4 " (6\%) were scored as the highest DPSI value in $36 \%$ of the dentate older individuals, indicating the need for periodontal surgery. 
Table 2 Demographic characteristics of study sample $\geq 65$ years $n=652 \quad 65-79$ years $n=185 \quad 80-89$ years $n=366 \quad>89$ years $n=101$

\begin{tabular}{lllll}
\hline Age (years) & & & & \\
Median & 83.0 & 75.0 & 84.0 & 92.0 \\
IQR Q1-Q3 & $79.0-88.0$ & $71.0-78.0$ & $82.0-87.0$ & $90.0-96.0$ \\
Mean (SD) & $83.0(7.7)$ & $74.0(4.6)$ & $84.4(2.8)$ & $94.2(5.7)$ \\
Gender (\%) & & & & \\
Female & 70.5 & 55.7 & 74.3 & 83.8 \\
Male & 29.5 & 44.3 & 25.7 & 16.2 \\
Language (\%) & & 68.7 & 65.9 & 62.4 \\
Dutch & 66.1 & 31.4 & 34.2 & 37.6 \\
French & 33.9 & & & \\
\hline
\end{tabular}

Table 3 Dental status, restorative index, and root surface condition

\begin{tabular}{|c|c|c|c|c|}
\hline & \multicolumn{4}{|l|}{ Age groups } \\
\hline & $\begin{array}{l}\geq 65 \text { years } \\
n=462\end{array}$ & $\begin{array}{l}65-79 \text { years } \\
n=146\end{array}$ & $\begin{array}{l}80-89 \text { years } \\
n=254\end{array}$ & $\begin{array}{l}>89 \text { years } \\
n=62\end{array}$ \\
\hline \multicolumn{5}{|l|}{ Number of natural teeth* } \\
\hline Mean (SD) & $6.9(8.1)$ & $8.0(8.9)$ & $6.9(7.9)$ & $4.4(5.5)$ \\
\hline Median & 4.0 & 5.0 & 3.0 & 3.0 \\
\hline 0 teeth $(\%)$ & 36.0 & 32.0 & 37.0 & 42.0 \\
\hline $1-9$ teeth $(\%)$ & 34.0 & 36.0 & 31.0 & 42.0 \\
\hline $10-20$ teeth $(\%)$ & 21.0 & 18.0 & 24.0 & 15.0 \\
\hline$>20$ teeth $(\%)$ & 9.0 & 14.0 & 8.0 & 1.0 \\
\hline $\mathrm{D}_{3} \mathrm{MFT}$ & $n=460$ & $n=146$ & $n=252$ & $n=62$ \\
\hline Mean (SD) & $20.3(9.0)$ & $18.5(9.4)$ & $21(8.6)$ & $21.8(8.8)$ \\
\hline Median & 24.0 & 21.0 & 25.0 & 27.0 \\
\hline Proportion $=0(\%)$ & 3.3 & 6.6 & 2.0 & 2.0 \\
\hline \multicolumn{5}{|l|}{$\mathrm{D}_{3}$} \\
\hline Mean (SD) & $1.8(3.11)$ & $1.7(2.6)$ & $1.9(3.3)$ & $1.9(3.3)$ \\
\hline Median & 0.0 & 0.5 & 0.0 & 0.0 \\
\hline \multicolumn{5}{|l|}{ M } \\
\hline Mean (SD) & $16.7(10.7)$ & $14.8(10.5)$ & $17.2(10.7)$ & $18.8(10.3)$ \\
\hline Median & 19.5 & 17.0 & 20.0 & 23.0 \\
\hline \multicolumn{5}{|l|}{$\mathrm{F}$} \\
\hline Mean (SD) & $1.8(3.3)$ & $1.9(3.5)$ & $1.9(3.4)$ & $1(2.3)$ \\
\hline Median & 0.0 & 0.0 & 0.0 & 0.0 \\
\hline Restorative index** & $n=282$ & $n=94$ & $n=153$ & $n=35$ \\
\hline Mean (SD) & $45.1(41.5)$ & $45.1(41.7)$ & $47(41.6)$ & $39.9(40.7)$ \\
\hline Median & 43.0 & 48.0 & 50.0 & 25.0 \\
\hline Proportion <1 (\%) & 77.0 & 78.0 & 76.0 & 8.03 \\
\hline \multicolumn{5}{|l|}{ Root surface condition } \\
\hline Mean number remaining teeth & 10.0 & 11.0 & 11.0 & 7.0 \\
\hline Persons $(\%)$ with exposed root surfaces & 71.0 & 90.0 & 77.0 & 78.0 \\
\hline Mean number of teeth with exposed root surfaces (SD) & $5.0(6.0)$ & $5.0(6.0)$ & $5.0(6.0)$ & $6.0(6.0)$ \\
\hline Persons (\%) with restored/decayed root surfaces & 42.0 & 40.0 & 42.0 & 45.0 \\
\hline Mean number of teeth with restored/decayed root surfaces (SD) & $1.0(3.0)$ & $1.0(2.0)$ & $1.0(3.0)$ & $1.0(2.0)$ \\
\hline
\end{tabular}

$*$ Residual roots excluded; $* *$ restorative index $=\mathrm{F} / \mathrm{D}+\mathrm{F}$ 


\section{Mucosal condition}

In nearly one out of four persons, 65 years of age or more, one or more oral mucosal lesions were observed (Table 4). The most frequently observed mucosal pathologies in the study sample were denture pressure ulcers $(10 \%)$, other mucosal lesions $(8.5 \%)$, cheilitis angularis $(5.6 \%)$, and flabby ridge $(5.2 \%)$. Small but not significant differences in the prevalence of oral mucosal lesions were ascertained between men and women. The most prominent difference was observed in the prevalence of cheilitis angularis with $8.1 \%$ for men and $4.5 \%$ for women.

\section{Functionality}

The threshold of 21 or more remaining teeth [33] was counted in $10 \%$ of nursing home residents and $13 \%$ of older people living at home (NS). In nearly one third of both dentate and edentate persons of 65-79 years, no occluding pairs were present; for the age groups 80-89 and $>89$, these proportions were 29 and $28 \%$, respectively. In the 65- to 79year-old age group, one $(2 \%)$, two $(6 \%)$, or three $(8 \%)$ occluding pairs were present in $16 \%$ of the cases, and this proportion decreased with age to $12 \%$ for the $80-89$-year-old age group and $8 \%$ for the $>89$-year-old age group (NS). The highest proportions were observed for persons with 8 occluding pairs resulting in a proportion of $32 \%$ in the age group 65-79 and $40 \%$ in the age group 80-89 and $>89$. In dentate people of 65 years of age or older, no occluding pairs were observed in $43 \%$ of the cases; $22 \%$ showed one or two occluding pairs, $21 \%$ showed three or four occluding pairs, and only $14 \%$ functioned with more than four occluding pairs. The mean number of teeth restored by fixed crowns or bridges was less than 0.71 .

\section{Prosthetic status}

The proportion of older people wearing a complete denture in the upper and lower jaws increased with age (Table 5). For nearly three out of four individuals over 89 years of age, a complete denture was observed in the upper jaw and, in half of the cases, a complete denture was present in the lower jaw. Additional analyses, not reported in the tables, revealed that in $40 \%$ of the study sample, a complete denture was present in both the upper and lower jaws. The proportions of persons with complete dentures in both jaws tended to increase with increasing age, with $31 \%$ for those $65-79$ years, $42 \%$ for those 80-89 years, and $50 \%$ for those $>89$ years (NS). This was also true for the objective treatment need, with $53 \%$ (235) of the upper dentures and $47 \%$ (208) of the lower dentures needing renewal, rebasing, or repair in the oldest age group $(>89)$ (NS) (Table 5).

\section{Oral hygiene}

Oral hygiene was far from adequate (Table 6), with the highest dental and denture plaque scores in the oldest age group (>89 years of age) (NS). The mean dental plaque observed in the oldest age group was 2.2 (SD 0.8), and in the same age group in $43 \%$ of dentures, at least $25 \%$ of the surface was covered with plaque.

Significant differences in dental plaque score were observed between care dependency groups with the highest mean score in persons with the highest levels of care dependency B (2.3; SD 0.68), C (2.0; SD 0.85), Cd (2.3; SD (0.77), A (1.8; SD 1.09), and O (1.5 SD 0.95) $(p<0.001)$. Nursing home residents 65 years of age or more showed higher dental plaque levels (2.1; SD 0.83) as compared to their counterparts residing at home $(1.5 ; \mathrm{SD} 1.03)(p<0.001)$. Within the study

Table 4 Oral mucosal lesions, by age group and sex

\begin{tabular}{|c|c|c|c|c|c|c|}
\hline & $\geq 65$ years $n=576$ & $65-79$ years $n=164$ & $80-89$ years $n=332$ & $>89$ years $n=80$ & Men $n=173$ & Women $n=403$ \\
\hline \multicolumn{7}{|l|}{ Proportion (\%) with } \\
\hline No lesion(s) & 74.0 & 73.0 & 74.0 & 74.0 & 74.0 & 73.7 \\
\hline Denture ulcer & 10.0 & 8.6 & 11.8 & 5.0 & 10.4 & 9.7 \\
\hline Irritation fibroma & 1.4 & 1.2 & 1.5 & 1.3 & $<1.0$ & 1.7 \\
\hline Flabby ridge & 5.2 & 5.5 & 5.1 & 5.0 & 5.2 & 5.2 \\
\hline Palatal hyperemia & 2.3 & 1.8 & 2.4 & 2.5 & 2.9 & 2.0 \\
\hline Hyperkeratosis & $<1.0$ & 0.0 & $<1.0$ & 1.3 & 0.0 & $<1.0$ \\
\hline White lesions & $<1.0$ & 0.0 & $<1.0$ & 1.3 & $<1.0$ & $<1.0$ \\
\hline Angular cheilitis & 5.6 & 3.7 & 7.2 & 2.5 & 8.1 & 4.5 \\
\hline Apthous lesion(s) & 1.6 & 1.8 & 1.5 & 1.3 & 1.2 & 1.7 \\
\hline Fistula & $<1.0$ & 0.0 & $<1.0$ & 0.0 & 0.0 & 0.7 \\
\hline Other & 8.5 & 10.4 & 6.6 & 12.5 & 5.8 & 7.9 \\
\hline
\end{tabular}


Table 5 Prosthetic status and treatment need, by age group

\begin{tabular}{|c|c|c|c|c|c|c|c|c|}
\hline & \multicolumn{2}{|c|}{$\geq 65$ years } & \multicolumn{2}{|c|}{$65-79$ years } & \multicolumn{2}{|c|}{$80-89$ years } & \multicolumn{2}{|c|}{$>89$ years } \\
\hline & $\begin{array}{l}n=625 \\
\text { Upper }\end{array}$ & $\begin{array}{l}n=618 \\
\text { Lower }\end{array}$ & $\begin{array}{l}n=180 \\
\text { Upper }\end{array}$ & $\begin{array}{l}n=181 \\
\text { Lower }\end{array}$ & $\begin{array}{l}n=354 \\
\text { Upper }\end{array}$ & $\begin{array}{l}n=348 \\
\text { Lower }\end{array}$ & $\begin{array}{l}n=91 \\
\text { Upper }\end{array}$ & $\begin{array}{l}n=89 \\
\text { Lower }\end{array}$ \\
\hline Proportion (\%) with no dentures & 23.8 & 36.3 & 32.2 & 48.6 & 22.1 & 32.2 & 14.3 & 27.0 \\
\hline One fixed bridge & $<1.0$ & 1.6 & $<1.0$ & 2.2 & 1.4 & 1.7 & 0.0 & 0.0 \\
\hline More than one fixed bridge & 2.2 & $<1.0$ & 1.7 & 0.0 & 2.5 & 1.2 & 2.2 & 2.3 \\
\hline Bridge(s) and acrylic resin based partial denture & $<1.0$ & $<1.0$ & 1.1 & 5.5 & $<1.0$ & 0.0 & 4.4 & 1.1 \\
\hline Bridge(s) and metal frame partial denture & $<1.0$ & $<1.0$ & 0.0 & 0.0 & 0.0 & $<1.0$ & 0.0 & 1.1 \\
\hline Acrylic resin-based partial denture & 5.8 & 7.8 & 5.6 & 0.0 & 6.2 & 9.2 & 2.2 & 6.7 \\
\hline Metal frame partial denture & 3.2 & 5.0 & 2.8 & 0.0 & 3.8 & 4.9 & 0.0 & 5.6 \\
\hline Removable complete denture & 58.9 & 41.4 & 50.0 & 32.0 & 59.9 & 44.0 & 72.5 & 50.6 \\
\hline Denture(s) not worn & 4.2 & 5.7 & 5.6 & 6.1 & 3.7 & 5.8 & 3.3 & 4.5 \\
\hline Prosthetic treatment need (\%) & $n=443$ & $n=443$ & $n=111$ & $n=111$ & $n=260$ & $n=260$ & $n=72$ & $n=72$ \\
\hline Denture renewal is necessary & 15.6 & 17.2 & 15.3 & 17.1 & 14.2 & 17.3 & 20.8 & 16.7 \\
\hline Denture renewal is advisable & 9.3 & 7.5 & 3.6 & 2.7 & 3.1 & 4.6 & 8.3 & 8.3 \\
\hline Denture relining or rebasing is necessary & 5.4 & 6.1 & 9.0 & 8.1 & 3.1 & 4.6 & 8.3 & 8.3 \\
\hline Denture relining or rebasing is advisable & 8.8 & 7.9 & 10.8 & 8.1 & 8.5 & 8.5 & 6.9 & 5.6 \\
\hline Denture repair is indicated & 2.1 & 0.0 & 1.8 & 0.0 & 2.3 & 0.0 & 1.4 & 0.0 \\
\hline
\end{tabular}

group of denture wearers, the proportion of persons with dentures "with no visible plaque" was lowest for the oldest age group (>89) compared to the other age groups. In this oldest age group, "no visible plaque" was found at $27 \%$ for the upper jaw and $21 \%$ for the lower jaw (NS).The proportion of denture wearers with dentures with "no visible plaque" was the lowest for persons with care dependency Cd (26\% upper denture; $24 \%$ lower denture), while the highest proportion was observed for people with care dependency A ( $42 \%$ upper denture; $33 \%$ lower denture). These differences were only significant for dentures in the upper jaw of people with care dependency Cd compared to $\mathrm{O}(p=0.01)$ and to $\mathrm{C}$ $((p=0.03)$ and for people with care dependency $\mathrm{O}$ compared to B $(p=0.03)$.
No significant gender differences were found for the dental and denture plaque levels and the presence of calculus on the remaining teeth or dentures.

\section{Discussion}

This national survey on oral health of frail older people aged 65 years or more, conducted for the first time in Belgium, demonstrated a high objective oral health treatment need with a high number of decayed teeth and exposed root surfaces and a high proportion older people suffering from periodontal inflammation. Furthermore, oral hygiene levels were poor and seemed to be influenced by age, care dependency, and place of

Table 6 Dental and denture hygiene, by age group

\begin{tabular}{|c|c|c|c|c|c|c|c|c|}
\hline & \multicolumn{2}{|l|}{$\geq 65$ years } & \multicolumn{2}{|c|}{$65-79$ years } & \multicolumn{2}{|c|}{$80-89$ years } & \multicolumn{2}{|l|}{$>89$ years } \\
\hline Dental plaque & $n=429$ & & $n=131$ & & $n=239$ & & $n=59$ & \\
\hline Mean (SD) & $1.9(1.0)$ & & $1.9(1.0)$ & & $1.8(1.0)$ & & $2.2(0.8)$ & \\
\hline Proportion of dentate with calculus (\%) & 57.0 & & 60.0 & & 55.0 & & 58.0 & \\
\hline \multirow[t]{2}{*}{ Proportion of persons with dentures with (\%) } & $n=410$ & $n=365$ & $n=102$ & $n=88$ & $n=238$ & $n=215$ & $n=70$ & $n=62$ \\
\hline & Upper & Lower & Upper & Lower & Upper & Lower & Upper & Lower \\
\hline No visible plaque & 39.5 & 35.3 & 41.2 & 36.4 & 42.4 & 39.1 & 27.1 & 21.0 \\
\hline Plaque $(<25 \%)$ & 26.8 & 24.4 & 26.5 & 22.7 & 28.6 & 25.6 & 21.4 & 22.6 \\
\hline Plaque $(>25<50 \%)$ & 17.6 & 17.8 & 16.7 & 17.8 & 16.4 & 16.3 & 22.9 & 27.4 \\
\hline Plaque (>50\%) & 11.7 & 9.1 & 11.8 & 5.7 & 9.2 & 8.4 & 20.0 & 16.1 \\
\hline Calculus & 39.6 & 43.8 & 31.6 & 36.9 & 40.2 & 44.2 & 49.3 & 51.7 \\
\hline
\end{tabular}


residence. In general, the worst oral hygiene and health was observed in the oldest age group $(>89)$. This indicates that, within the high-risk group of frail older people 65 years of age or more, the oldest ones are at the highest risk for developing oral health diseases, and this should be taken into account in oral health care management.

The observed mean $\mathrm{D}_{3}$ MFT (20.3) is lower than the data reported for Europe (24.5) [34], Norway (23.2-2004) [8], Austria (25.6-2007) [15], and Germany (26.4-1990/1993) [18]. A restorative index of less than one in $77 \%$ of the cases in the present study, however, indicates the largest treatment backlog as compared to other European countries (France, Germany, Sweden, and UK). This can possibly be explained by a high proportion (53.4\%) of older people with dementia syndrome within this study sample. As recently demonstrated by Ellefsen et al. [20], the prevalence of caries is higher in people with dementia syndrome.

Data regarding periodontal disease in the oldest age groups are scarce and difficult to compare or to interpret. Nevertheless, the present data accord with data of epidemiological studies in Norway [8], Austria [15], and Germany [11] indicating a high prevalence of gingival inflammation.

Although removable dentures were considered when counting occluding pairs, a very small number of occluding pairs was observed in the study sample possibly hampering oral functionality, with a negative effect on nutrition. This was already shown by Lamy et al. reporting in 2009 that the poor status of prosthetic oral health among nursing home residents in Liège (Wallonia, Belgium) resulted in an increased difficulty in eating hard foods, an increased consumption of mashed food, and a decreased pleasure in eating, with a higher risk of malnutrition [16]. A recent systematic review confirms tentative evidence of an independent association between oral health status and malnutrition in the older people residing in long-term care facilities [35]. Malnutrition in the older population is strongly underestimated and even minimized. However, many stakeholders start to recognize this problem.

The findings concerning oral mucosal lesions compare well with those in the literature, showing that oral mucosal lesions in edentulous or partly edentulous older individuals are mainly related to ill-fitting or inadequately maintained removable dentures. In European surveys [8, 9, 17, 21, 22, 24, 36], the proportions of older people residing in nursing homes with oral mucosal lesions varied between 10.8 and $48 \%$.

The naturalness and characteristic property of an observational field study can jeopardize the validity leading to some limitations in the study. At the end of the survey, several dental examiners mentioned difficulties in examining the frailest persons and, in some cases, an examination was impossible. This substantial loss of data gives rise to response bias with an underestimation of the treatment backlog.

The observed proportion of edentate older persons residing in Belgian nursing homes was $32 \%$. This contrasts sharply with the $64 \%$ of edentate older persons in a random sample of 359 older persons residing in 19 nursing homes in the Ghent region as reported in a previous study [6]. The discrepancy between the results of the present Belgian study and the Flemish one [6] can be explained possibly by geographical and socio-economic differences and/or selection bias, supposing that in the present study, dentate older people were more likely to participate.

Despite a global response rate of $73 \%$, the study results should be interpreted with caution. The response rate was $100 \%$ for nursing home residents while for older people living at home the response rate differed markedly between Flanders $(71 \%)$, Brussels (13\%), and Wallonia (0\%) resulting in an overall response rate of $52 \%$. Within the study sample, only $33 \%$ of the participants were living at home. This proportion does not correspond to the ratio found in the population (53\%), thus resulting in a substantial unintended under sampling of this study group. Furthermore, none of the persons examined who were living at home supported by daily domiciliary care were from the Walloon region and just two were from Brussels. The results of this study group are therefore only representative for Flanders. In this survey, the proportion of older people with different care dependency scales corresponded with the proportion of people aged 65 years or more in the population.

Furthermore, it should be mentioned that the mean age of 83.0 years was biased by an unintended oversampling of the age group 80-89 years of age. Since it was nearly impossible to record exact selection probabilities for the different selection parameters, a weighted analysis was not possible.

This national data collection on the oral health conditions of frail older people aged 65 or more was ordered by the NIHDI to gain essential information, which is required to direct appropriate oral health care strategies. The results emphasize the need for an integrated oral health care programme which includes tailor-made oral health promotion by implementing procedures, protocols, standard practices and facilities for oral health care delivery for all the frail older regardless of their place of residence. A great need exists for more coordinated, seamless continuing oral health care services, tailored to the actual needs of older individuals, both at home or in institutions [37, 38]. Accordingly, dentists and dental auxiliaries should be encouraged and funded to offer on-site domiciliary oral health care.

It is beyond all doubt that oral health care should start with good daily oral hygiene, the cornerstone of preventive oral health care. The importance of oral hygiene has recently been highlighted in a systematic review which has shown the positive, preventive effects of oral hygiene on pneumonia and respiratory tract infections in older people who are hospitalised and older nursing home residents. The absolute risk reduction (ARR) ranged from 6.6 to $11.7 \%$ [39]. 
Since most oral diseases can be prevented by appropriate care, identifying older adults before they manifest oral health deterioration is important. Nevertheless, the results of the Health Interview Survey in Belgium [40] showed that with increasing age, decreasing proportions of the participants had visited the dentist during the last 12 months. Therefore, more efforts should be made by all (oral) health care workers to promote regular dental visits by all age groups, emphasising the need for adults aged 55 or older.

\section{Conclusions}

This survey demonstrated a very poor oral health status among care-dependent older people aged 65 years or more, and age, residence, and care dependency seemed to have some influence. Oral hygiene was poor and an important need for restorative and prosthetic treatment was observed. Therefore, the development of new models of oral health services, with emphasis on prevention and health promotion, improved access to professional dental care, and on-site oral health care delivery emerges. However, in the long term, the most important future challenge of oral health care policies is to identify older adults before they begin to manifest such oral health deterioration. Regular dental visits should be strongly promoted by all (oral) health care workers during the lifespan of all persons including older adults.

Acknowledgments The authors would like to thank the examined persons with special needs, all members of the Advisory Committee, Stefaan Hanson (coordinator), and the National Institute for Health and Disability Insurance for commissioning and financing the Pilot study "Oral Health in Persons with Special Needs."

\section{Compliance with ethical standards}

Conflict of interest The authors declare that they have no competing interests.

\section{References}

1. Lafortune G, Balestat G. Disability Study Expert Group Members. Trends in severe disability among older people: assessing the evidence in 12 OECD countries and the future implications. OECD Health Working Papers: 2007. http://www.google.com/search?hl= en \& $\mathrm{q}=\mathrm{OECD}+\mathrm{HEALTH}+\mathrm{W}$ ORKING + PAPERS $+2007+$ disability $+\& b$ tnG $=$ Search

2. RIZIV (NIHDI). 2007: Confidential data files

3. Declercq A, Van Audenhoven T (2004) Services for supporting family carers of elderly people in Europe: characteristics, coverage and usage: national background report for Belgium. Leuven, Eurofamcare

4. WHO 2003 World oral health report. http://www.who.int/oral health/publications/report03/en/
5. Scientific Institute of Public Health Epidemiology Unit 2004 Health interview survey in Belgium. http://www.iph.fgov.be/ epidemio/epien/index4.htm

6. De Visschere LM, Grooten L, Theuniers G, Vanobbergen JN (2006) Oral hygiene of elderly people in long-term care institutions - a cross-sectional study. Gerodontology 23:195-204

7. Kalsbeek H, Schuller AA, Kivit MM, de Baat C (2006) Mondzorg in verpleeg-en verzorgingshuizen en instellingen voor verstandelijk gehandicapten. Nederlands Tijdschr Tandheelkunde 113:90-95

8. Samson H, Strand GV, Haugejorden O (2008) Change in oral health status among the institutionalized Norwegian elderly over a period of 16 years. Acta Odontol Scand 66:368-373

9. Söderpalm Andersen E, Söderfeldt B, Kronström M (2006) Oral health and treatment need among older individuals living in nursing homes in Skaraborg, Vastra Gotaland, Sweden. Swed Dent J 30:109-115

10. Ferro R, Besostri A, Strohmenger L, Mazzucchelli L, Paoletti G, Senna A, et al. (2008) Oral health problems and needs in nursing home residents in Northern Italy. Community Dent Health 25:231-236

11. Jäger S, Köster-Schmidt A, Schade M, Heudorf U (2009) Mundhygiene und Mundgesundheit bei Bewohnern von Altenpflegeheimen. Bundesgesunsheitsbl 52:927-935

12. Tramini P, Montal S, Valcarcel J (2007) Tooth loss and associated factors in long-term institutionalised elderly patients. Gerodontology 24:196-203

13. Thomson WM (2004) Dental caries experience in older people over time: what can the large cohort studies tell us? Br Dent J 196:89-92

14. Saunders Jr RH, Meyerowitz C (2005) Dental caries in older adults. Dent Clin N Am 49:293-308

15. Gluhak C, Arnetzl GV, Kirmeier R, Jakse N, Arnetzl G (2010) Oral status among seniors in nine nursing homes in Styria, Austria. Gerodontology 27:47-52

16. Lamy M, Mojon P, Kalykakis G, Legrand R, Butz-Jorgensen E (1999) Oral status and nutrition in the institutionalized elderly. J Dent 27:443-448

17. Cohen C, Tabarly P, Hourcade S, Kirchner-Bianchi C, Hennequin $\mathrm{M}$ (2006) Quelles réponses aux besoins en santé buccodentaire des personnes âgées en institution. Presse Méd 35:1639-1648

18. Nitschke I (2001) Geriatric oral health issues in Germany. Int Dent J 51:235-246

19. Adam H, Preston AJ (2006) The oral health of individuals with dementia in nursing homes. Gerodontology 23:99-105

20. Ellefsen B, Holm-Pedersen P, Morse DE, Schroll M, Andersen BB, Waldemar G (2008) Caries prevalence in older persons with and without dementia. J Am Geriatr Soc 56:59-67

21. Peltola P, Vehkalahti MM, Wuolijoki-Saaristo K (2004) Oral health and treatment needs of the long-term hospitalised elderly. Gerodontology 21:93-99

22. Triantos D (2005) Intra-oral findings and general health conditions among institutionalized and non-institutionalized elderly in Greece. J Oral Pathol Med 34:577-582

23. Kossioni AE, Karkazis HC (1999) Socio-medical condition and oral functional status in an older institutionalised population. Gerodontology 16:21-28

24. Sweeney MP, Williams C, Kennedy C, Macpherson LM, Turner S, Bagg J (2007) Oral health care and status of elderly care home residents in Glasgow. Community Dent Health 24:37-42

25. Frenkel H, Harvey I, Newcombe RG (2000) Oral health care among nursing home residents in Avon. Gerodontology 17:33-38

26. Leroy R, Declerck D (2013) Oral health care utilization in children with disabilities. Clin Oral Investig 17(8):1855-1861. doi:10.1007/ s00784-012-0874-2

27. Leroy R, Declerck D (2013) Objective and subjective oral health care needs among adults with various disabilities. Clin Oral Investig 17(8):1869-1878. doi:10.1007/s00784-012-0879-x

28. Leroy R, Declerck D (2013) Oral health-care utilization in adults with disabilities in Belgium. Eur J Oral Sci 121:36-42 
29. Katz S, Down TD, Cash HR, Grotz RC (1970) Progress in the development of the index of ADL. The Gerontologist 10:20-30

30. der Velden V (2009) The Dutch periodontal screening index validation and its application in The Netherlands. J Clin Periodontol 36: $1018-1024$

31. Silness J, Löe H (1964) Periodontal disease in pregnancy. II. Correlation between oral hygiene and periodontal condition. Acta Odontol Scand 22:121-135

32. Augsburger RH, Elahi JM (1982) Evaluation of seven proprietary denture cleansers. J Prosthet Dent 47:356-359

33. Slade GD, Spencer AJ, Roberts-Thomson KF (2007) Australia's dental generations. The National Survey of Adult Oral Health 2004-06. Australian Institute of Health and Welfare, Canberra

34. Petersen PE, Kandelman D, Arpin S, Ogawa H (2010) Global oral health of older people - call for public health action. Community Dent Health 27:257-267

35. Van Lancker A, Verhaeghe S, Van Hecke A, Vanderwee K, Goossens J, Beeckman D (2012) The association between malnutrition and oral health status in elderly in long-term care facilities: a systematic review. Int J Nurs Stud 49:1568-1581
36. Frenkel H, Harvey I, Newcombe RG (2001) Improving oral health in institutionalised elderly people by educating caregivers: a randomised controlled trial. Community Dent Oral Epidemiol 29: 289-297

37. Hally J, Clarkson JE, Newton JP (2003) Continuing dental care for Highlands elderly: current practice and attitudes of dental practitioners and home supervisors. Gerodontology 20:88-94

38. Weening-Verbree L, Huisman-de Waal G, van Dusseldorp L, van Achterberg T, Schoonhoven L (2013) Oral health care in older people in long term care facilities: a systematic review of implementation strategies. Int J Nurs Stud 50:569-582

39. Sjogren P, Nilsson E, Forsell M, Johansson O, Hoogstraate J (2008) A systematic review of the preventive effect of oral hygiene on pneumonia and respiratory tract infection in elderly people in hospitals and nursing homes: effect estimates and methodological quality of randomized controlled trials. J Am Geriatr Soc 56:2124-2130

40. Health Interview Survey. Scientific Institute of Public Health (WIVISP). https://his.wiv-isp.be/SitePages/Home.aspx 